\title{
1 A UTILIZAÇÃO DOS MAPAS MENTAIS COMO INSTRUMENTO DE PERCEPÇÃO DO ESPAÇO GEOGRÁFICO
}

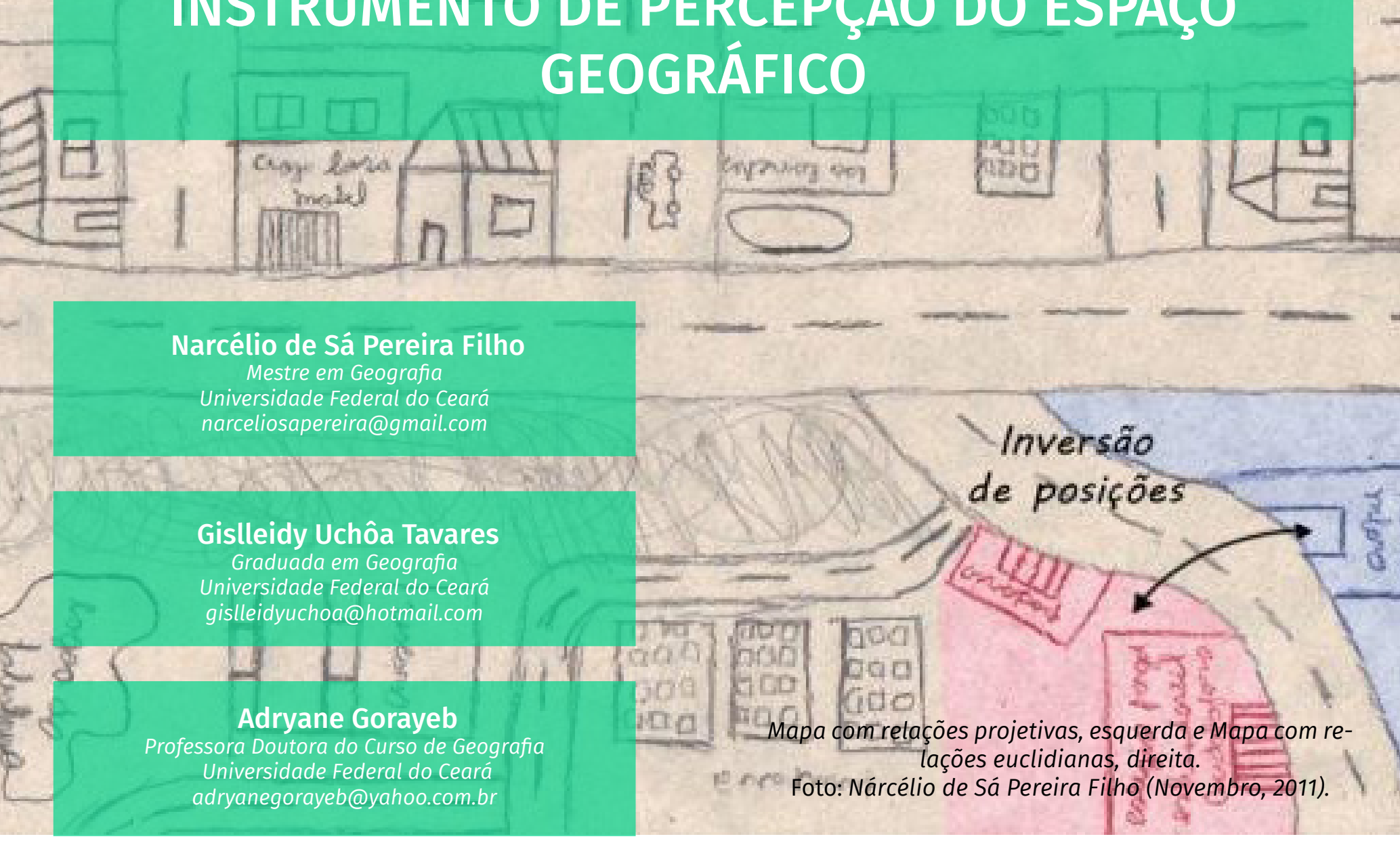

\section{RESUMO}

O desenvolvimento da Cartografia sempre acompanhou o progresso da civilização. A história dos mapas é mais antiga que a própria história da escrita, isto se pensarmos na história como a documentação sobre os fatos passados. A Cartografia, a partir do desenvolvimento das técnicas de educação, passa a ser uma grande aliada no processo de ensino e aprendizagem. Um produto da aliança entre essas duas vertentes, Cartografia e Educação, é o mapa mental, que através da sensibilidade do educador, ao analisar o produto de seu educando, consegue relacionar o mapa elaborado com o relacionamento desse aluno com o seu meio, seu modo de pensar, sua análise geográfica do mundo e etc. Dessa forma, o presente trabalho teve como ponto de partida diversos estudos que enfocam a importância da utilização da Cartografia em sala de aula e de um processo contínuo de educação cartográfica. Para a realização do estudo, foi feita uma pesquisa com os alunos do ensino fundamental II de duas escolas, uma particular e outra pública (da rede municipal de ensino), ambas localizadas no mesmo bairro no município de Caucaia, Região Metropolitana de Fortaleza, Ceará. Durante a pesquisa, foi solicitado que os estudantes mapeassem o caminho por eles percorrido no trajeto casa - escola, utilizando-se os preceitos do mapa mental. A partir desse produto cartográfico foi possivel analisar a forma como os alunos representavam o espaço sensivel a eles e a interação entre essas respostas cognitivas com as propostas dos Parâmetros Curriculares Nacionais (PCNs) para a alfabetização cartográfica, bem como a utilização das operações espaciais propostas por Jean Piaget. Outro aspecto tocante à pesquisa relacionou a produção dos mapas mentais como ferramenta de percepção do espaço geográfico sensivel aos alunos, onde se consideram os estudantes como elaboradores de mapas, especialmente dos fenômenos do seu cotidiano. Desse modo, a pesquisa visou evidenciar a importância da utilização da Cartografia em sala de aula como ferramenta de percepção do espaço geográfico e de apoio ao professor no processo de ensino e aprendizagem em Geografia.

\section{ABSTRACT}

The development of cartography has always followed the progress of civilization. The story of the maps is older than the history of writing, if we think of history as the documentation of past events. Cartography from the development of technical education, becomes a great ally in the teaching and learning. A product of the alliance between these two directions, mapping and education, is the mental map, where through the sensitivity of the educator, when analyzing the product of your student can relate the map drawn with the student's relationship with its environment, its mode of thinking, analysis of the geographical world, etc. Thus the present work has as its starting point many studies that focus on the importance of using maps in the classroom and an ongoing process of cartographic education. For the study, was done one research with elementary school students II in two schools, one private and one public (municipal schools), both located in the same neighborhood in the city of Caucaia, Metropolitan Region of Fortaleza, Ceará . During the study, we asked students that mapeassem the path they traveled between home and school, using the precepts of the mental map. From cartographic product was could analyze how students represented space sensitive to them and the interaction between these cognitive responses to the proposals of the National Curriculum Parameters (PCN's) for cartographic literacy, and the use of space operations proposed by Jean Piaget. Another aspect related to the research concerning the production of mental maps as a tool of perception of geographic space sensitive to students, which considers students as makers of maps, especially the phenomena of everyday life. Thus, the research aimed to highlight the importance of the use of cartography in the classroom as a tool of perception of geographical space and teacher support in the teaching and learning in Geography.

Key words: Literacy Mapping. Mind Mapping. Geographical Space.

Palavras - chave: Alfabetização Cartográfica. Mapas Mentais. Espaço Geográfico. 


\section{INTRODUÇÃO}

O desenvolvimento da Cartografia, desde épocas remotas até os dias atuais tem acompanhado o próprio progresso da civilização. A Cartografia aparece em seu estágio mais elementar sob a forma de mapas itinerários feitos pelas populações nômades da antiguidade. Com o advento do comércio entre os países e com o consequente aparecimento dos primeiros exploradores e navegadores que descobriram novas terras e novas riquezas e ampliou o horizonte geográfico conhecido, o ser humano sentiu necessidade de se localizar sobre a superficie da Terra. Estabeleceu-se, portanto, o marco inicial da Cartografia como ciência.

Com o desenvolvimento e a evolução da educação, a Cartografia passou a ser uma grande aliada da mesma, e um produto da união entre essas duas vertentes é o mapa mental que, através da sensibilidade do educador, ao analisar o produto de seu educando consegue relacionar o mapa elaborado com o relacionamento desse aluno com o seu meio, seu modo de pensar, sua análise geográfica do mundo e etc.

O mapa mental, por tanto, é capaz de revelar como o aluno vê e interpreta o meio em que vive, sendo capaz de identificar como ele concebe a sociedade no qual está inserido ocorrendo, assim, denúncias das irregularidades do espaço, do mesmo modo que também mostra suas atribuições de valores diferenciados para o mesmo espaço, ou seja, os locais com os quais indiretamente ele mais se identifica. Nesse sentido, o mapa mental é capaz de dar um diagnóstico de dificuldades relacionadas à percepção do espaço geográfico, bem como dos princípios básicos da geografia para alunos em diferentes niveis de aprendizagem.

Nesse contexto, a pesquisa apresentada tem como principal objetivo compreender como a utilização de mapas mentais possibilita a percepção e materialização do espaço geográfico, independentemente do nível socioeconômico e educacional em que se encontra o educando. Para tanto, foi realizada uma pesquisa com os alunos do ensino fundamental II de dois colégios, um particular e outro público (da rede municipal de ensino), ambos localizados no mesmo bairro, em Caucaia, município da Região Metropolitana de Fortaleza, Ceará.

\section{MATERIAIS E MÉTODOS}

O estudo foi realizado nos meses de setembro, outubro e novembro de 2011, em duas escolas localizadas na cidade de Caucaia, Região Metropolitana de Fortaleza, sendo uma delas da rede municipal de ensino e outra da rede particular. Todas as crianças que participaram da pesquisa estavam regularmente matriculadas nas instituições de ensino, cursando o ensino fundamental II, do quinto ao nono anos. Essas duas escolas foram selecionadas por estarem situadas no mesmo bairro, Parque Guadalajara, e por se localizarem uma em frete à outra, favorecendo então a análise e comparação do material resultante.

As escolas selecionadas foram 0 Colégio Parque Estudantil Guadalajara - CPEG, da rede de ensino privado, e a E.E.I.E.F. Sete de Setembro, da rede municipal de ensino. Ambas as escolas se localizam no bairro Parque Guadalajara, município de Caucaia CE (Figura 1).

\section{POPULAÇÃO E AMOSTRAGEM}

A população pesquisada incluiu os 150 alunos, nas duas escolas, do período diurno que frequentavam as duas escolas, do quinto ao nono ano do ensino fundamental II, e 

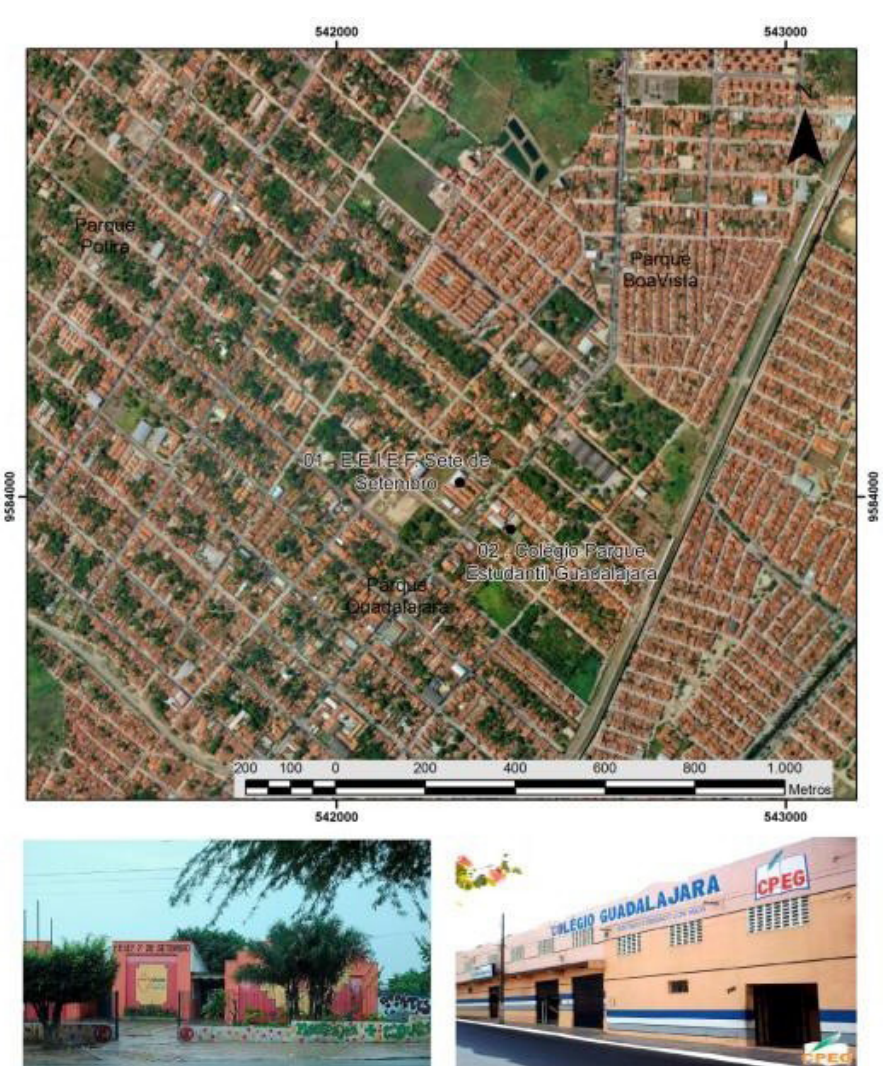

01 . E.E.I.E.F. Sete de Setembro

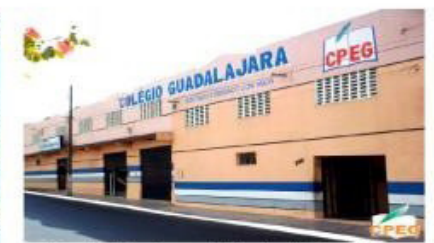

02. Colégio Parque Estudantil Guadalajara

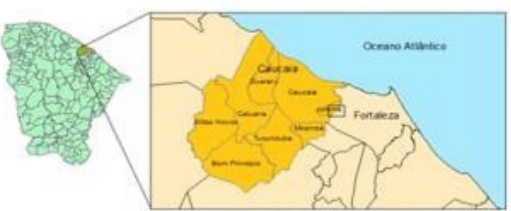

Figura 1. Localização das escolas participantes do estudo. Elaboração: Narcélio de Sá Pereira Filho (Novembro, 2011).

com idades variando entre 11 e 17 anos. Dos 150 alunos que compunham a população, 69 correspondiam à instituição particular e 81 à instituição pública. Para o estudo, foram selecionados mapas de 15 alunos de cada colégio que serviram como população da pesquisa, caracterizando um total de 30 alunos que, por sua vez, corresponde a $20 \%$ da população total trabalhada.

A série escolar foi considerada como fator principal, de forma que alunos de todas as séries estudadas em ambas as escolas estivessem presentes na amostra. Já a idade foi utilizada como fator de seleção secundário, de modo que na amostra final a heterogeneidade das idades da população geral pesquisada estivesse representada nos resultados finais.

\section{DESCRIÇÃO DOS MATERIAIS E COLETA DOS DADOS}

Os materiais utilizados na produção dos mapas mentais foram papel branco A4, lápis de cor preto. Esses materiais foram escolhidos pelos alunos de forma que cada um utilizasse o que mais estivesse familiarizado. A atividade ocorreu na própria sala de aula onde os alunos estudavam e durou, em média, 50 minutos em cada turma (Figura 2). Ao final desse tempo foram recolhidos os mapas de cada aluno.

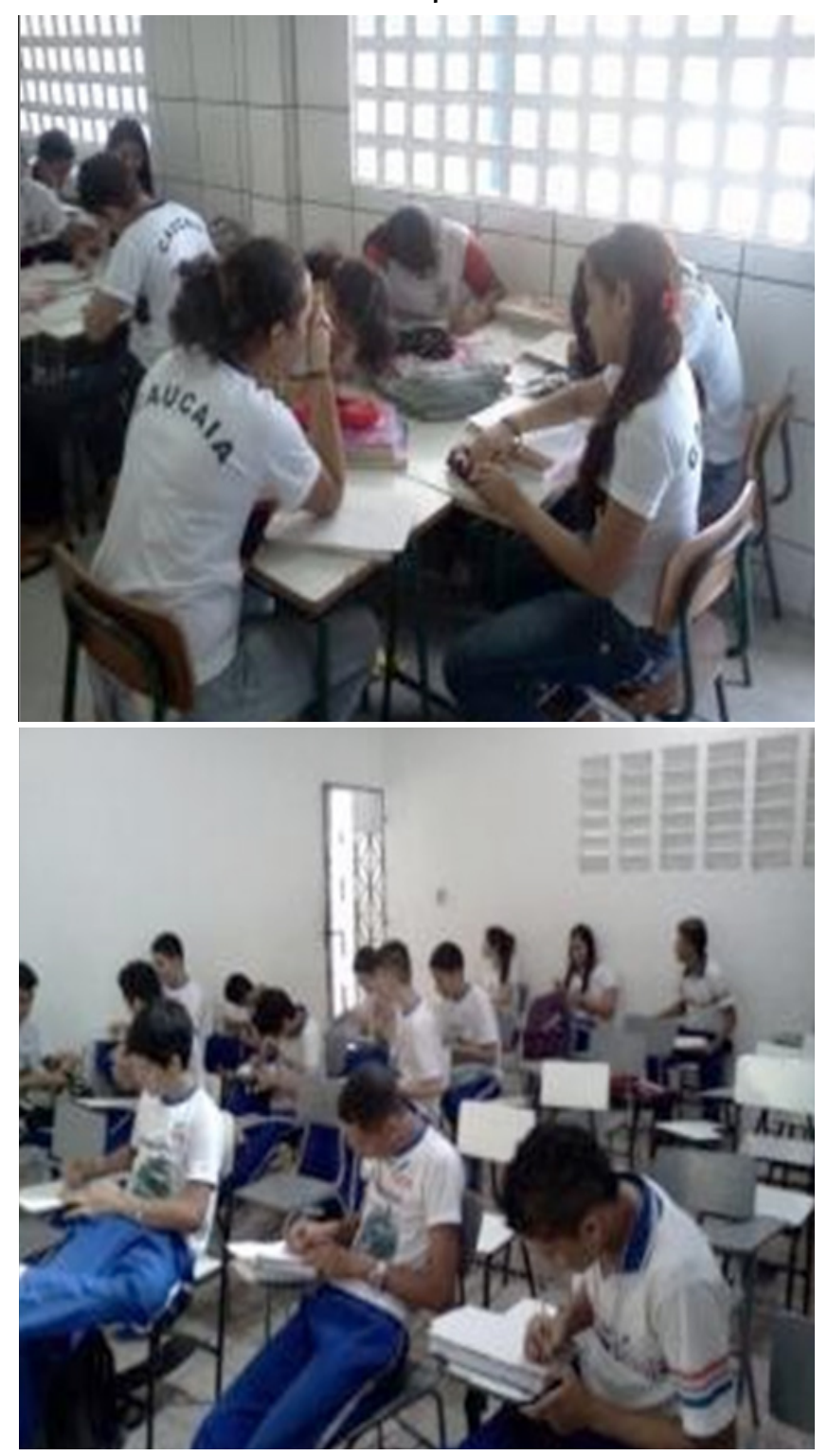

Figura 2. Momentos das atividades de produção dos mapas mentais. Acima na E.E.I.E.F. Sete de Setembro e abaixo no Colégio Parque Estudantil Guadalajara. Foto: Narcélio de Sá Pereira Filho (Novembro, 2011). 


\section{TÉCNICA DE ANÁLISE}

$\mathrm{Na}$ análise dos materiais cartográficos resultantes da pesquisa, ou seja, dos mapas mentais dos alunos, buscou-se analisar variáveis em cada mapa, procurando estabelecer niveis de aprendizado da cartografia e da noção de espaço.

Para a análise do material, foram utilizados critérios ligados às relações espaciais construídas pelos alunos. Dessa forma, buscou-se analisar o desenvolvimento individual dos alunos diante das noções de alfabetização cartográfica proposta pelos PCNs, que supõe o desenvolvimento das noções de: visão obliquá e visão vertical; imagem tridimensional e imagem bidimensional; alfabeto cartográfico; construção da noção de legenda; proporção e escala; e lateralidade/ referências e orientação (BRASIL, Secretaria de Educação Fundamental, 1998).

Procurou-se também relacionar os mapas mentais com a utilização das operações espaciais dadas pelos três tipos de relação com o espaço que basearam as perspectivas analíticas propostas por Piaget, sendo elas: relações topológicas, relações projetivas e relações euclidianas ou métricas (PIAGET, 1969, apud OLIVEIRA, 1996).

\section{DISCUSSÃO}

\section{A CARTOGRAFIA E A CARTOGRAFIA ESCOLAR}

A Cartografia pode ser definida segundo (CASARIN, 2004) como uma ciência e ao mesmo tempo uma técnica; é entendida como uma arte em levantar dados, redigir e divulgar mapas. De acordo com a Organização das Nações Unidas, a Cartografia pode ser definida também como a ciência que trata da concepção, estudo, produção e utilização de mapas (ONU, 1949, apud OLIVEIRA, 1997).
O conceito da Cartografia, hoje aceito sem maiores contestações, foi estabelecido em 1966 pela Associação Cartográfica Internacional $(\mathrm{ACl})$, e posteriormente, ratificado pela UNESCO, no mesmo ano: VEIRA, 1996).

A Cartografia apresenta-se como o conjunto de estudos e operações científicas, técnicas e artísticas que, tendo por base os resultados de observações diretas ou da análise de documentação, se voltam para a elaboração de mapas, cartas $e$ outras formas de expressão ou representação de objetos, elementos, fenômenos e ambientes fisicos e socioeconômicos, bem como a sua utilização (UNESCO, 1966 apud IBGE, 1998, p.10).

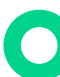

A cartografia torna-se recurso fundamental para o ensino de Geografia. Isso porque sua linguagem gráfica - o mapa - permite que os alunos avancem na leitura e representação do espaço. A esse respeito, os Parâmetros Curriculares Nacionais (PCNs) afirma que:

A Cartografia é um conhecimento que vem se desenvolvendo desde a pré-história até os dias de hoje. Esta linguagem possibilita sintetizar informações, expressar conhecimentos, estudar situações, entre outras coisas, sempre envolvendo a ideia de produção do espaço: sua organização $e$ distribuição (BRASIL, 1998, p.33).

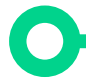

o processo de aprendizagem cartográfica exige uma participação do sujeito no meio externo, mediante experiência. Essa experiência pode ser diretamente sobre os objetos (experiência física) ou indiretamente (experiência matemática) (Figura 3).

$\mathrm{Na}$ experiência física existe uma ação do sujeito no sentido de descobrir as propriedades de tais objetos. A experiência matemática implica agir sobre as ações exercidas pelos sujeitos. A abstração, nesse caso, prende-se não mais às propriedades 
dos objetos, mas às ações exercidas sobre eles, isto é, às coordenações das ações, ou ainda às estruturas mentais do sujeito.

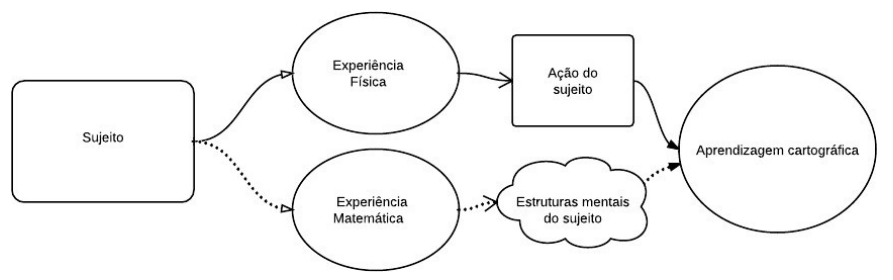

Figura 2. Processo de Aprendizagem Cartográfica mediante experiências fisicas e matemáticas.

Fonte: Adaptado de Oliveira (1979).

Segundo a Secretaria de Educação Fundamental (1998, p.33), o papel da escola é criar as condições fundamentais para que os alunos construam conhecimentos sobre a linguagem cartográfica em dois sentidos: i) como pessoas que representam e codificam o espaço e ii) como leitores das informações expressas. Para isso, deve-se considerar a ação dos alunos como elaboradores de mapas, especialmente dos fenômenos do seu cotidiano, pois assim "ele será estimulado a codificar, através de significados atribuídos a coisas de sua vivência e da sua imaginação" (CALLAI, 2005 apud OLIVEIRA, 2008, p. 56).

Ainda conforme a Secretaria de Educação Fundamental (1998, p.33), a cartografia deve ser compreendida "como um instrumento na aproximação dos lugares e do mundo". Para isso, o objetivo básico da alfabetização cartográfica proposta pelos PCNs supõe o desenvolvimento das noções de: 1. Visão oblíqua e visão vertical; 2. Imagem tridimensional e imagem bidimensional; 3. Alfabeto cartográfico; 4. Construção da noção de legenda; 5. Proporção e escala; 6. Lateralidade / referências e orientação.

\section{MAPAS MENTAIS COMO INSTRUMENTO DE PERCEPÇÃO DO ESPAÇO GEOGRÁFICO}

A utilização dos mapas mentais em sala de aula surge como uma ferramenta não só de percepção do espaço geográfico, e sim de desmitificação dessa premissa do tecnicismo dos recursos cartográficos para alunos e professores. Os mapas mentais são representações do vivido, são os mapas que construímos ao longo de nossa história com os lugares de vivência. No mapa mental, é possível fazer a representação do saber percebido, o lugar se apresenta tal como ele é, com sua forma, histórias concretas, simbólicas, cujo imaginário é reconhecido como uma forma de apreensão do lugar (NOGUEIRA, 1994 apud SIMIELLI, 1999).

Uma importante característica dos mapas mentais se refere ao fato de que estes são produzidos através de qualquer tipo de conhecimento que a pessoa tenha do local representado, ou seja, o mapa pode transmitir a imagem de um lugar vivido ou não pelo indivíduo. Como afirma Nogueira em relação aos mapas mentais:

São representações mentais que cada indivíduo possui dos espaços que conhece. Este conhecimento é adquirido direta (através de percepções dos lugares que lhe é familiar, os espaços vividos) ou indiretamente através de leituras, passeios, $e$ informações de terceiros (revista, livros, jornais, televisão, rádio, etc.) (NOGUEIRA, 1994, p.03).

A funcionalidade dos mapas mentais feitos por crianças é expressa por (BALE, 1887 apud Moraes, 2008, p.63): os mapas mentais elaborados por crianças podem ser utilizados como: a) instrumento de diagnóstico, b) guia de informação e c) atividade de instrução. Portanto, eles possuem características que ajudam o professor nestas três grandes áreas.

Estas três funções afirmam pontualmente a aplicabilidade dos mapas mentais no ensino de Geografia. Como instrumento de diagnóstico os mapas servem como uma forma de identificar a concepção de espaço pelas crianças. Já como guia de 
informação os mapas fornecem ao professor a capacidade de identificar e analisar as relações afetivas estabelecidas pelo aluno dentro do espaço representado. Por último, como atividade de instrução os mapas mentais em sala de aula servem para iniciar o processo de aprendizagem da criança na Cartografia e, partindo deste pressuposto, o professor pode trabalhar com os dados obtidos nos mapas apresentados pelas crianças (MORAES, 2008).

Tendo em vista o primeiro mapa de que temos conhecimento e os atuais, altamente sofisticados, há toda uma evolução de métodos, técnicas, materiais e teorias, que estão em acordo com o próprio desenvolvimento e progresso da ciência e da tecnologia. Assim, o mapa, acima de tudo é um modo de expressão, comunicação e linguagem gráfica, ocupa e sempre irá ocupar um lugar de destaque na Geografia, pois, revela-se um instrumento de trabalho, com finalidades de registro e armazenamento de informação, enfocando aspectos físicos, sociais, culturais, econômicos e políticos.

Desta forma, a utilização dos mapas em sala de aula deve possibilitar a leitura, interpretação ea manipulação dasinformações neles contidos, já que eles, os mapas, nos permitem o domínio espacial e a síntese de fenômenos que ocorrem em um determinado espaço. Portanto, ressalta-se a desmitificação da cartografia como um simples desenho, já que todo esse processo e a utilização desses conceitos cartográficos enfatizam aos alunos não como meros reprodutores e sim sujeitos participantes na construção de um material cartográfico dotado de significados.

\section{RESULTADOS}

Os resultados permitiram extrair conclusões gerais que enfocam a importância da utilização dos mapas mentais no ensino de Geografia como ferramenta de percepção do espaço geográfico, bem como um instrumento de ensino e auxílio para os professores.
Através da aplicação dos mapas mentais em sala de aula percebeu-se que os conteúdos relacionados à alfabetização cartográfica não são, em sua totalidade, compreendidos e utilizados pelos alunos.

Outro resultado relaciona a utilização das operações espaciais propostas por Piaget, onde se percebe a evolução nos tipos de relações espaciais utilizada pelos alunos na representação do espaço geográfico sensivel no trajeto casa - escola.

No tocante às noções de alfabetização cartográfica proposta pelos PCNs, percebese que há uma facilidade por parte dos estudantes em se trabalhar com noções como: visão oblíqua e visão vertical, alfabeto cartográfico, lateralidade, referências e orientação. Praticamente, todos os alunos conseguiram utilizar essas variáveis nos mapas mentais produzidos.

Dentro da amostra estudada $100 \%$ dos alunos conseguiram trabalhar com as noções de visão oblíqua e visão vertical e alfabeto cartográfico e $94 \%$ deles utilizaram nos mapeamentos a alguma noção de lateralidade, referências e orientação.

É notável que essa facilidade na utilização das noções de visão oblíqua e visão vertical e alfabetos cartográficos se dão pela aproximação das experiências comuns entre os alunos (Figura 4). A visão oblíqua representada no mapa nada mais é que a forma que os alunos têm de representar a forma como eles percebem inicialmente o ambiente, já que essa é a visão que temos no dia a dia. Já a visão vertical tem sua aproximação na utilização de mapas em sala de aula e a utilização cada vez maior de ferramentas, como o Google Maps. 

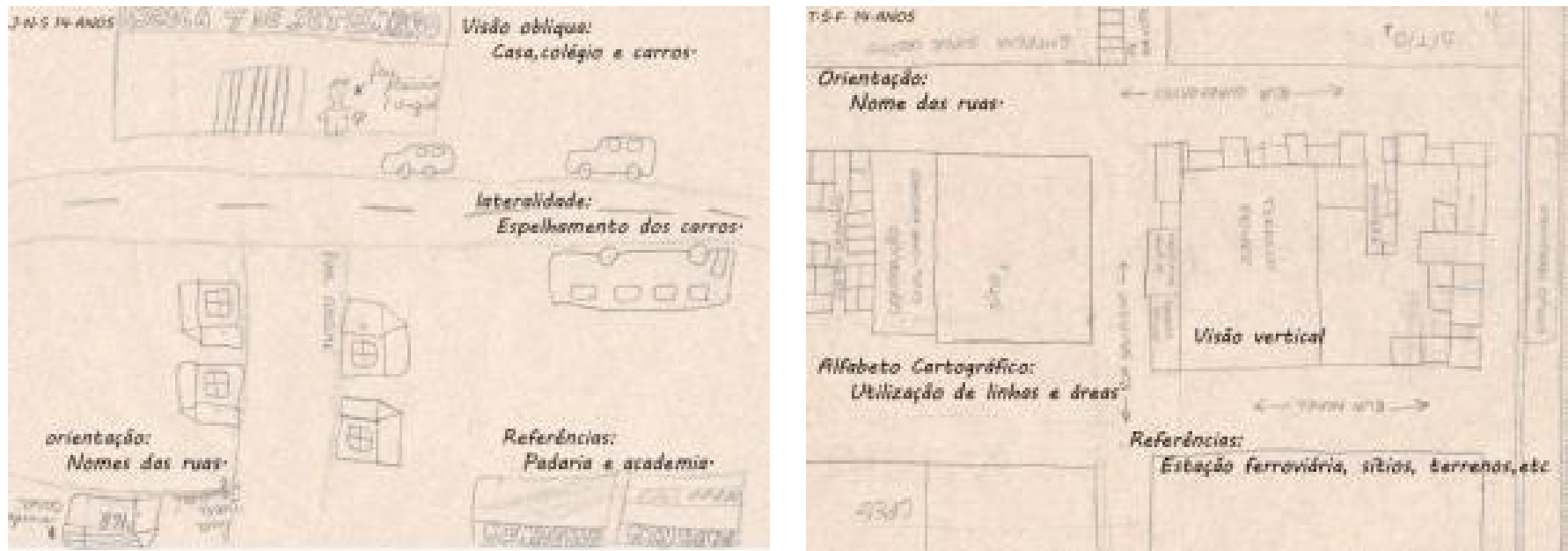

Figura 4. Mapas com exemplos de visão obliqua e visão vertical, alfabeto cartográfico, lateralidade, referências e orientação

Foto: Nárcélio de Sá Pereira Filho (Novembro, 2011).

As noções de lateralidade, referências e orientação presentes na maioria dos mapas produzidos estão relacionadas à forma como os alunos representam as direções e as orientações dos objetos no mapa. Alguns alunos, apesar de utilizar essas noções, tiveram dificuldades de localizar corretamente os principais lugares mapeados, principalmente pela dificuldade em se orientar no percurso e de confundir direita com esquerda.

$\mathrm{Na}$ análise dos mapas mentais produzidos pelos alunos, percebeu-se certa dificuldade na utilização das seguintes noções de alfabetização cartográfica: a noção de imagem tridimensional e imagem bidimensional, a construção da noção de legenda e noções de proporção e escala (Figura 5). Dentro da análise, $70 \%$ dos alunos utilizaram de alguma forma a noção de proporção e escala, já em relação à utilização de representações tridimensional e bidimensional apenas $40 \%$ dos alunos utilizaram alguma dessas noções de representação nos seus mapas. A principal dificuldade encontrada no estudo foi a subutilização das noções de legenda, em queda amostragem apenas seis alunos utilizaram legendas de alguma forma nos seus mapas, totalizando $20 \%$ da amostra.
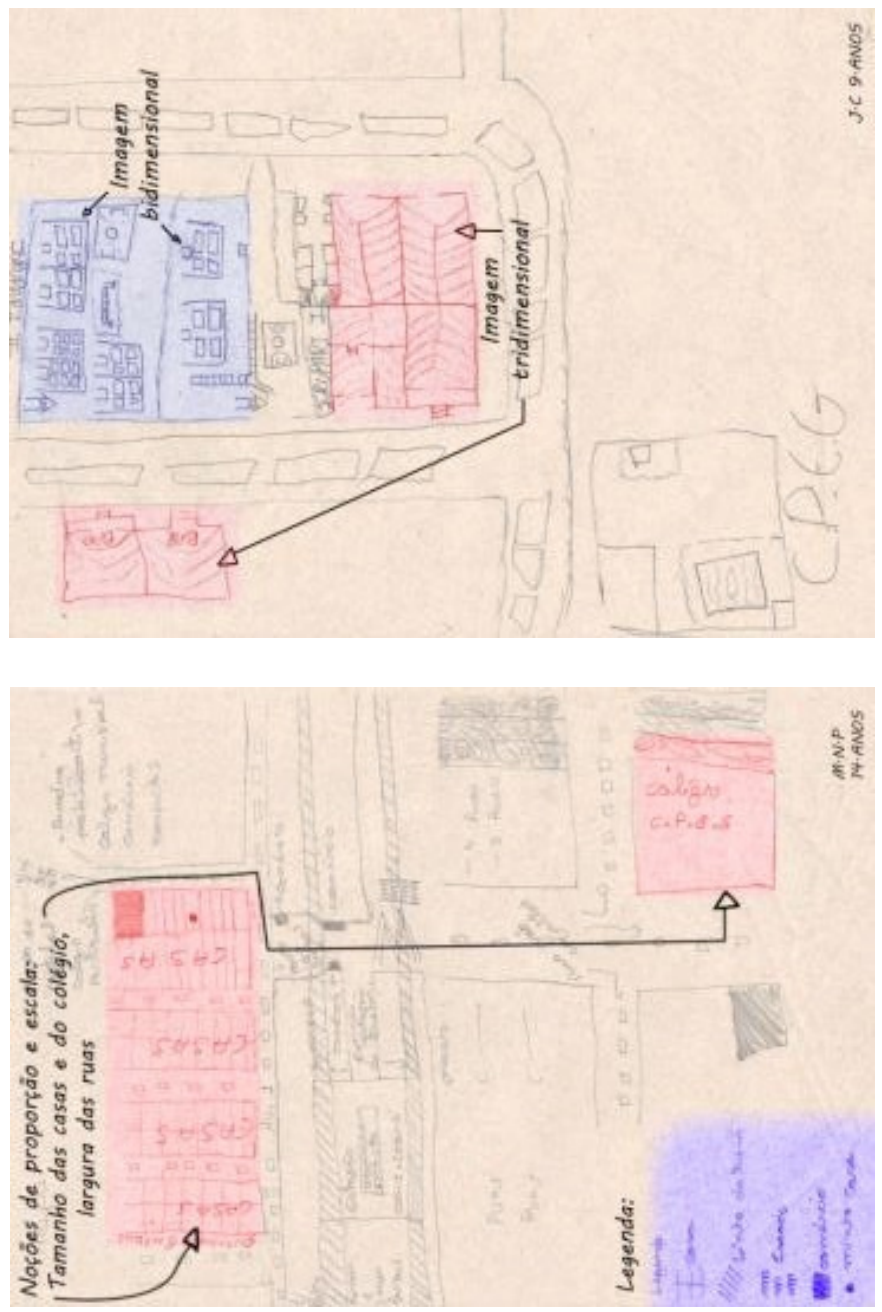

Figura 5. Mapas com exemplos de noção de imagem tridimensional e imagem bidimensional, a construção da noção de legenda e noções de proporção e escala. Foto: Nárcélio de Sá Pereira Filho (Novembro, 2011). 
Sobre os tipos de relações espaciais, pode-se constatar que mais da metade dos alunos estudados, um total de 17 entre os 30 (57\%), utilizou relações espaciais projetivas na confecção dos seus mapas mentais. Já 11 alunos, 37\% do total, utilizaram relações espaciais euclidianas e apenas dois alunos, $6 \%$ do total, utilizaram relações espaciais topológicas para representar o trajeto da escola para casa.

Os resultados da pesquisa em relação às operações espaciais mostram que há uma evolução na forma de representação do espaço geográfico. Já que para Piaget a gênese das representações se dá nas relações topológicas. Utilizadas por dois alunos, essa representação pressupõe relações de perto e longe, dentro e fora, entre outras. Os mapas apresentados por esses alunos são os mais simples, onde geralmente são representados a casa, a escola e o trajeto, bastante simplificado (Figura 6).

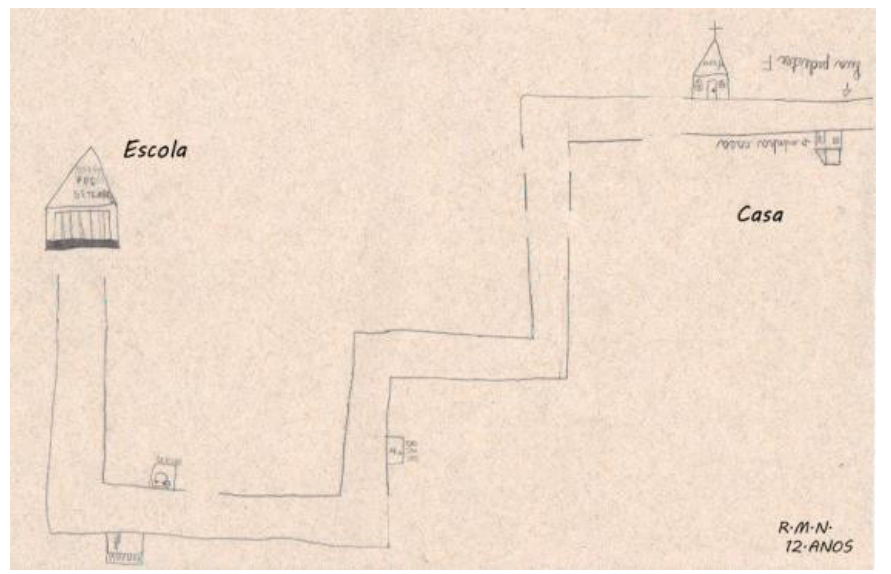

Figura 6. Mapa com relações topológicas Foto: Nárcélio de Sá Pereira Filho (Novembro, 2011).

Após a evolução das experiências topológicas surgem as experiências projetivas, que foram utilizadas por 17 alunos. 0 aluno necessita situar objetos em relação aos demais objetos em uma determinada perspectiva, lançando aqui as noções de acima- abaixo, direita-esquerda. Nesse momento, os mapas tomam um aspecto elaborado, onde o aluno adota uma perspectiva e representa os elementos por ele conhecidos e, através deles, tenta relacionar os demais. É comum nessa etapa a confusão entre a direita e a esquerda, resultando mapas onde os elementos aparecem em posições invertidas (Figura7).
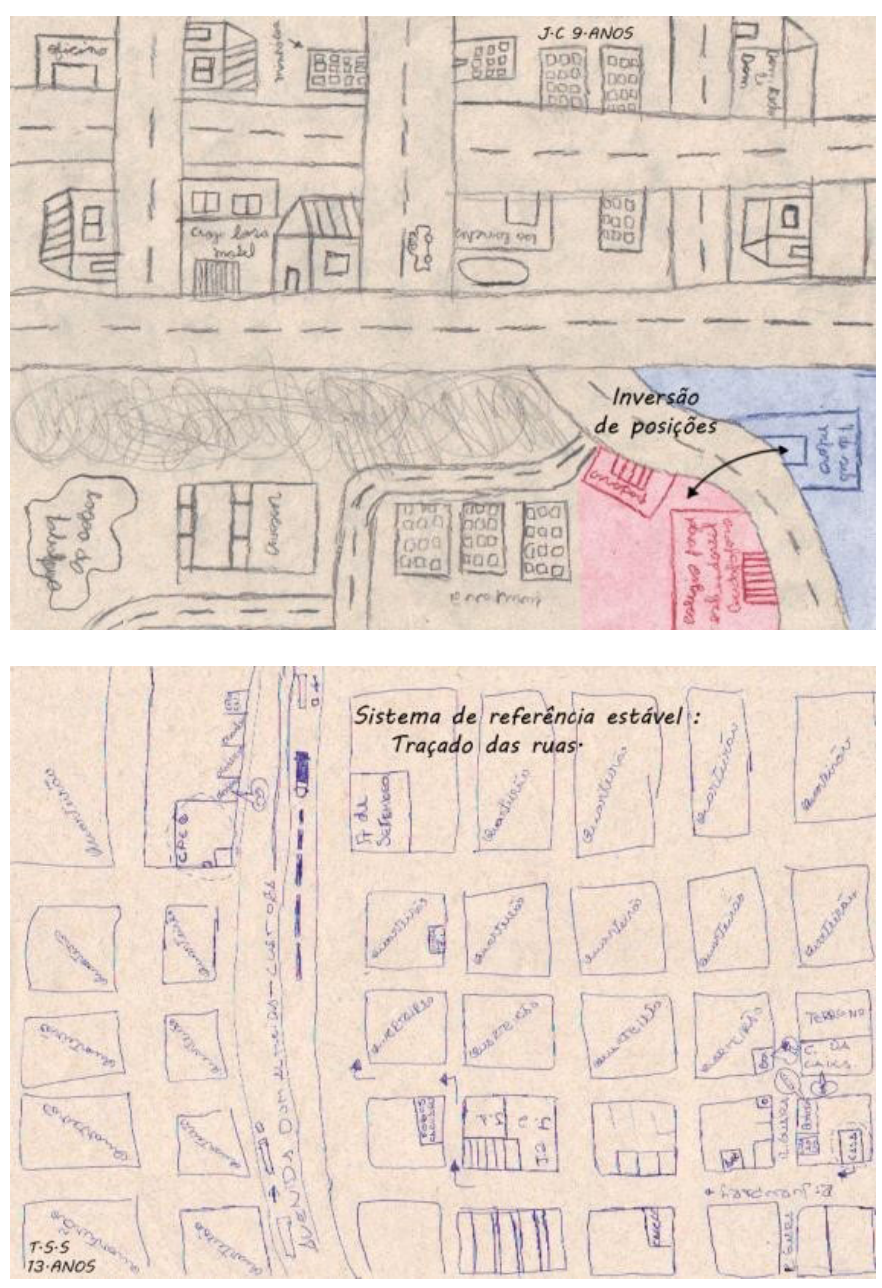

Figura 7. Mapa com relações projetivas, esquerda e Mapa com relações euclidianas, direita.

Foto: Nárcélio de Sá Pereira Filho (Novembro, 2011).

Paralelamente à evolução dos processos projetivos ocorre a evolução das experiências euclidianas, utilizadas por 11 alunos. Essa relação, assim como a projetiva, é derivada das relações topológicas sendo que tem como principal característica a fundamentação da noção de distância e a equivalência através de igualdades matemáticas.

Nas projeções Euclidianas, diferentemente das relações projetivas que 
se baseiam em um objeto conhecido e da relação desses com os demais, a coordenação dos objetos é feita por meio de um sistema de referência estável que funciona como um ponto de partida para o mapeamento. No caso, todos os alunos que se utilizaram desse tipo de relação se basearam no traçado das ruas para referenciar seus desenhos (Figura 7).

Quando se analisa os mapas mentais como ferramenta de percepção do espaço geográfico sensivel aos alunos, podem-se obter inúmeras variáveis relacionadas ao grau de percepção do espaço geográfico, dentre as quais: distribuição espacial dos alunos de ambas as escolas e suas implicações no mapeamento, e as formas diferenciadas de percepção de pontos de referência comuns.

Realizada a análise, pode-se perceber que a distribuição espacial das residências dos alunos é diferenciada, principalmente quando se consideram os mapas produzidos em cada colégio. Pode-se evidenciar que apesar do público dos colégios serem diferenciados, já que uns estudam em uma escola pública e outros em uma escola privada, ambos residem no mesmo bairro. Porém, deve-se considerar que a escola particular possui alguns alunos que residem em bairros mais distantes do município de Caucaia, bem como alguns alunos vindos de bairros de Fortaleza como o Conjunto Ceará e a Granja Portugal. Desta forma, a escola privada recebe alunos que moram em um raio que pode chegar a 3000 metros de distância da escola, já a escola pública, que possui nos seus públicos alunos que residem em suas proximidades, recebe alunos em um raio que chega ao máximo de 1500 metros de distância da escola.

Essa distância em relação à escola reflete-se no material desenvolvido, já que os alunos que moram mais próximo à escola tiveram uma capacidade maior de representar os seus trajetos de casa para a escola. Em contrapartida, os alunos que moravam mais distantes e que, em sua maioria, realizavam o trajeto casa - escola de carro ou ônibus tiveram maior dificuldade em representar o percurso no papel.

Dessa forma, enquanto os alunos que moravam mais próximo dos colégios conseguiam representar os pontos de referências como, a casa de colegas, lojas, padarias, o nome das ruas, etc. os que moravam mais longe conseguiam representar apenas alguns pontos gerais. Para os que moravam em Fortaleza, por exemplo, um dos únicos pontos de referência era a passagem pela linha férrea, que separa os dois municípios.

Então, foi possivel observar mapas mais ricos em detalhes para os alunos que residem mais próximo do colégio que os demais que realizavam trajetos mais longos, embora tenha sido registrado mapas com muitos detalhes confeccionados por alunos que moravam a mais de dois quilômetros da escola.

Essa problemática relacionada ao distanciamento do indivíduo demonstra que o mapeamento mental baseia-se na subjetividade e nas experiências através dos sentidos e das vivências do indivíduo. Essas experiências são amplamente trabalhadas durante o processo da representação espacial.

Outro aspecto interessante que foi perceptível foi à diferenciação do ponto de vista dos alunos em relação ao espaço comum, ou seja, dos ambientes comuns entre os alunos. Essa diferenciação está implícita no processo de mapeamento mental, já que esse é resultado de experiências e abstrações do indivíduo. Desta forma, a representação desses lugares comuns, embora em alguns momentos, sejam próximas entre um indivíduo, são em essência diferenciadas pelas ações e abstrações individuais.

Um exemplo importante foi no tocante à representação dos dois colégios. O primeiro aspecto interessante foi à representação, ou não, do colégio vizinho, muito dos alunos em sua representação do trajeto das suas casas para o colégio deixavam de representar o outro colégio nos seus mapas. Ou seja, os 
alunos do CPEG não representavam o Colégio Sete de Setembro em seus mapas e viceversa, embora um colégio se situe em frete ao outro, a uma distância de aproximadamente 20 metros.

Dentre as 30 amostras analisadas dos 15 alunos do CPEG apenas cinco alunos representaram o Sete de Setembro enquanto dos 15 alunos do Sete de Setembro dois representaram o CPEG. Um dos fatores que explica essa questão é a própria indicação da atividade em realizar o mapeamento da casa para a escola, sendo que alguns que não mapearam o outro colégio chegaram a mapear pontos de referência ou o nome das ruas próximas ao colégio vizinho.

Outro exemplo que ilustra a forma como as experiências individuais são representadas nos mapas está na forma diferenciada de como os alunos do CPEG e do Sete de Setembro mapearam o CPEG. O CPEG tem sua entrada principal voltada para a Av. Dom Almeida Lustosa da mesma forma que o Sete de Setembro, assim todos os alunos do Sete de Setembro ao mapear o CPEG o fez voltado para essa avenida (Figura 8).

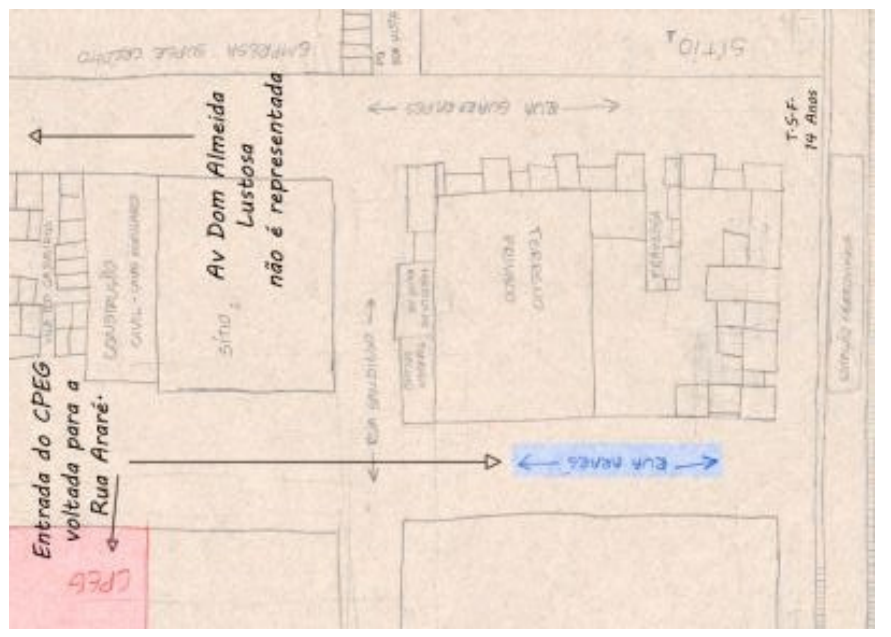

Figura 8. Mapas das representações diferenciadas de referências comuns.

Foto: Nárcélio de Sá Pereira Filho (Novembro, 2011).

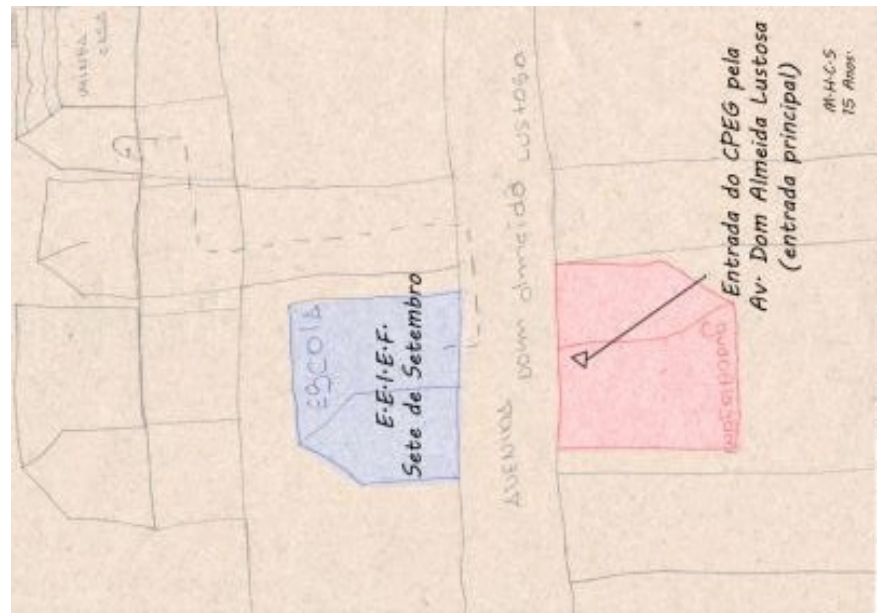

Figura 8. Mapas das representações diferenciadas de referências comuns.

Foto: Nárcélio de Sá Pereira Filho (Novembro, 2011).

Já os alunos do CPEG em sua maioria o mapearam voltado para a Rua Araré, que é perpendicular à Av. Dom Almeida Lustosa, isso porque a entrada dos alunos fica voltada para essa rua. Dessa forma, reforça-se a ideia que o mapeamento mental evidencia as visões individuais de cada aluno baseado inicialmente nas experiências fisicas, sendo essas as mais fortes na construção de imagens mentais, já que são resultados de experiências reais e não fruto de abstrações, ou seja, de experiências matemáticas

\section{CONCLUSÃO}

A utilização de ferramentas cartográficas em sala de aula é uma realidade. 0 professor de Geografia precisa trabalhar o conteúdo relacionado à Ciência Cartografia. A grande problemática em torno disso está no fato do professor utilizar as ferramentas que a Cartografia dispõe como o mapa, o globo, entre outras, como recurso visual, com o objetivo de apenas ilustrar e mesmo "concretizar" a realidade. Essa abordagem acaba por desconsiderar aspectos importantes da alfabetização cartográfica, já que acaba por desprezar etapas importantes do desenvolvimento mental do aluno. 
Através das análises dos mapas mentais foi possível caracterizar a utilização, por meio dos alunos, as noções básicas propostas pelos Parâmetros Curriculares Nacionais - PCNs no que se refere à alfabetização cartográfica. Bem como a utilização das operações espaciais propostas por Piaget, levando em consideração a utilização dos tipos de relações espaciais utilizada pelos alunos na representação do espaço geográfico sensivel.

O mapa mental pode servir também como diagnóstico para o professor do desenvolvimento cognitivo dos alunos. Percebeu-se através da análise do material produzido pelos alunos, que os mapas mentais podem evidenciar inúmeras variáveis relacionadas ao grau de percepção dos alunos em relação ao espaço geográfico. Isso porque a mapa mental é uma resposta individual de experiências e de qualquer tipo de conhecimento que o indivíduo tenha do local representado, ou seja, o mapa pode transmitir a imagem de um lugar vivido ou não pelo indivíduo. Dentre as variáveis obtidas com a pesquisa pode-se entender, a partir dos mapas mentais, a distribuição espacial dos alunos de ambas as escolas e suas implicações no mapeamento, e as formas diferenciadas de percepção de pontos de referência comuns.

Dessa forma, pode-se afirmar que os mapas mentais podem ser utilizados como ferramenta de diagnóstico de dificuldades relacionadas à percepção do espaço geográfico, bem como dos princípios básicos da Geografia para alunos em diferentes niveis de aprendizagem. Ademais, os mapas mentais servem como indicador da evolução no processo de alfabetização cartográfica dos alunos, já que fornecem ao professor a capacidade de identificar e analisar as relações afetivas estabelecidas pelo aluno dentro do espaço representado. Finalmente, os mapas mentais podem ser utilizados como ferramenta de percepção do espaço geográfico sensivel aos alunos, sendo capaz de representar as formas mais subjetivas de percepção do espaço através das experiências físicas e matemáticas em relação ao espaço geográfico por eles mapeados.

o mapa mental é, portanto, uma importante ferramenta já que é capaz de mostrar como o aluno vê e interpreta o meio em que vive, a sociedade onde ele está inserido dentre outras percepções que são inerentes às experiências individuais de cada aluno. O mapa mental, assim, é capaz de dar um diagnóstico das dificuldades relacionadas à percepção do espaço geográfico, bem como dos princípios básicos da Geografia para alunos em diferentes níveis de aprendizagem.

\section{REFERÊNCIAS}

BRASIL. Secretaria de Educação Fundamental. Parâmetros Curriculares Nacionais - PCNs. Brasília: MEC/SEF, 1998.

CASARIN, Rosália. Algumas reflexões sobre a Cartografia no contexto da Geografia. Revista Ciência Geográfica. ano X, vol. X, no. 3, set/ dez.2004, p. 254-258.

IBGE. Noções Básicas de Cartografia. Rio de Janeiro: Instituto Brasileiro de Geografia e Estatística, 1998. Disponível em: <http://www. ibge.gov.br>. Acesso em: 20 de Nov. 2011.

MORAES, L. B. de. A cidade em mapas: Goiânia e sua representação no ensino de Geografia. 1 ed. Ed. Vieira, Goiânia, 2008.

NOGUEIRA, Amélia Regina Batista. Mapa Mental: recurso didático no ensino de Geografia no 10 grau. São Paulo: USP, 1994. 208p. (Dissertação de Mestrado)

OLIVEIRA, Ana Keyla Pereira de ; Fábio, Wankler (2008). ALFABETIZAÇÃO CARTOGRÁFICA NA ESCOLA: uma leitura feita através dos mapas. Revista ACTA Geográfica. ano 2,no. 4, jun/ dez.2008, p. 55-65. 
OLIVEIRA, Lívia. Estudo metodológico e cognitivo do mapa., São Paulo: USP/Instituto de Geografia, 1979.

OLIVEIRA, Lívia. Percepção e representação do espaço geográfico. In: DEL RIO, Vicente e OLIVEIRA, Lívia de. (Orgs.) Percepção ambiental: a experiência brasileira. São Paulo: Studio Nobel; São Carlos: Ed. UFSCAR. p.187212.

SIMIELLI, M. E. R. Cartografia no ensino fundamental e médio. In: CARLOS, Ana Fani Alessandri (org.). A Geografia na sala de aula. São Paulo: Contexto, 1999. - (Repensando o ensino). p. 92-108. 